\title{
Effect of Sicilian pasture feeding management on content of $\alpha$-tocopherol and $\beta$-carotene in cow milk
}

\author{
V. M. Marino, ${ }^{* 1}$ I. Schadt, ${ }^{*}$ S. Carpino, ${ }^{*}$ M. Caccamo, ${ }^{*}$ S. La Terra, ${ }^{*}$ C. Guardiano, ${ }^{*}$ and G. Licitra*† \\ ${ }^{*}$ Consorzio di Ricerca Lattiero Casearia (CoRFiLaC), 97100 Ragusa, Sicilia, Italy \\ †Dipartimento di Scienze delle Produzioni Agrarie e Alimentari (DISPA), Agriculture Faculty, Catania University, 95123 Catania, Sicilia, Italy
}

\begin{abstract}
This study was performed to evaluate $\alpha$-tocopherol and $\beta$-carotene contents of pasture milk under ordinary Sicilian farming conditions. Fourteen dairy farms were allocated into 2 balanced groups on the basis of cultivated (CULT) or spontaneous (SPO) pasture type feeding. Bulk milk per farm was collected 4 times from February through April at 3-wk intervals. Pasture botanical and diet composition, diet nutritional quality, milk yield and composition were estimated each time. Pasture intake levels were calculated based on feed analyses, hay and concentrate amounts fed, and milk yield and chemical composition. According to pasture intake, the farms were split into low pasture intake (LPI; $<29.5 \%$ of dry matter) and high pasture intake (HPI; $>29.5 \%$ of dry matter) groups. Milk samples per farm were analyzed for $\alpha$-tocopherol and $\beta$-carotene contents by HPLC. The SPO group had higher levels of $\alpha$-tocopherol and $\beta$-carotene in milk $(0.7$ and $0.3 \mathrm{mg} / \mathrm{L}$, respectively) and milk fat (19.0 and $7.5 \mathrm{mg} / \mathrm{kg}$ fat, respectively) compared with the CULT group in milk ( 0.5 and $0.2 \mathrm{mg} / \mathrm{L}$, respectively) and milk fat (14.6 and $4.9 \mathrm{mg} / \mathrm{kg}$, respectively). High pasture intake compared with LPI increased $\alpha$-tocopherol in milk fat (18.0 and $16.0 \mathrm{mg} / \mathrm{kg}$ of fat, respectively). However, only in the SPO (not in CULT), HPI compared with LPI increased milk $\alpha$-tocopherol (0.8 vs. $0.6 \mathrm{mg} / \mathrm{L}$, respectively), milk $\beta$-carotene ( 0.3 vs. $0.2 \mathrm{mg} / \mathrm{L}$, respectively), and milk fat $\beta$-carotene ( 8.4 vs. $6.6 \mathrm{mg} / \mathrm{kg}$, respectively). Results may be related to the different botanical composition of the respective pasture types and pasture intake. Spontaneous pasture compared with CULT contained a higher mass proportion of Asteraceae, Fabaceae, Cruciferae, Euphorbiaceae, and Malvaceae plants. Milk and milk fat $\alpha$-tocopherol levels were higher on testdays (TD)-1, TD-2, and TD-4 compared with TD-3. For HPI farms, milk fat $\beta$-carotene content was higher on the first 2 TD compared with the last 2 TD. These
\end{abstract}

Received May 7, 2013.

Accepted September 25, 2013.

${ }^{1}$ Corresponding author: v.marino@corfilac.it differences could be related to plant biological stage. On Sicilian dairy farms, the highest milk $\alpha$-tocopherol and $\beta$-carotene contents may be obtained feeding high levels of SPO pasture in the spring.

Key words: milk, $\alpha$-tocopherol, $\beta$-carotene, pasture

\section{INTRODUCTION}

Milk contains biologically active nutrients such as $\alpha$-tocopherol and $\beta$-carotene that have beneficial effects on human health, including the prevention and treatment of diseases (Bhat and Bhat, 2011). $\alpha$-Tocopherol and $\beta$-carotene act as powerful antioxidants by scavenging free radicals that, in excessive amounts, can cause deleterious effects in different biological molecules (Lindmark-Månsson and Åkesson, 2000) as well as off-flavor development in milk (Havemose et al., 2006; Slots et al., 2007). These fat-soluble vitamins are not synthesized by cows but their presence in milk derives from feedstuff or diet-supplemented synthetic compounds (Slots et al., 2009). Thus, there has been an increased scientific interest in the study of dietary effects and the development of new feeding strategies for dairy cows to enhance the nutraceutical value of milk. Previous studies showed that milk from cows grazing fresh pasture is richer in fat-soluble vitamins than milk from cows kept indoors and fed mainly conserved forage (Agabriel et al., 2007; Ellis et al., 2007). Moreover, several factors, including pasture botanical composition, plant maturity, pasture intake, grazing time, and season, may affect milk fat-soluble vitamin composition (Nozière et al., 2006; Marino et al., 2012). Ballet et al. (2000) considered the leaf to stem ratio, in addition to species, to be the main factor influencing $\alpha$-tocopherol and $\beta$-carotene contents in fresh pasture. Plants with a higher proportion of leaves tend to contain higher levels of $\alpha$-tocopherol and $\beta$-carotene. At advanced stages of growth, legumes are better sources of $\beta$-carotene compared with grasses, because of the higher proportion of leaves in legumes. At the flowering stage, however, legumes and grasses have approximately the same mean levels of $\alpha$-tocopherol. 
Studies reported that higher botanical diversity in pasture is associated with higher concentrations of nutraceutical compounds as PUFA and fat-soluble vitamins (Martin et al., 2004). Collomb et al. (2002) reported that PUFA content was higher in milk from cows grazing mountain pasture than in that derived from monocultures of lowland pasture. Many studies in the literature regarding the effects of cow feeding strategies on milk vitamin levels compared grass with legume-rich pastures. There is still limited knowledge concerning the fat-soluble vitamin content of milk as affected by individual plant species and families and by pasture composition.

Ragusa is historically one of the most important provinces of Sicilian dairy production. Many dairy farms in Ragusa are characterized by a rearing system based on the feeding of the fresh pasture, which is available from November until the end of May. The local pasture grows under the Mediterranean subtropical climate. Pasture starts growing in autumn after the first rain falls and is not interrupted by winter frost but by the hot and dry summer period. According to a previous study (Marino et al., 2012), Sicilian spring pasture was more heterogeneous compared with autumn pasture. During spring, most plants were at the flowering stage and milk fat-soluble vitamin contents were highest.

Cows graze cultivated pastures on most of the farms in Ragusa, although spontaneous pasture feeding is still used. Spontaneous pastures, in general, are characterized by high biodiversity compared with cultivated pastures. More than 100 plant species belonging to over 25 families occur in spontaneous pasture of the Ragusa province (Licitra et al., 1997), whereas cultivated pastures usually contain only species of the Poaceae and Fabaceae plant families.

The aim of the present study was to investigate quality of spontaneous and cultivated pastures and pasture feeding management on Sicilian dairy farms during spring by evaluating $\alpha$-tocopherol and $\beta$-carotene contents of pasture milk under ordinary Sicilian farming conditions.

\section{MATERIALS AND METHODS}

\section{Farms and Experimental Conditions}

Commercial dairy farms producing Protected Denomination of Origin Ragusano cheese were chosen because disciplinary regulation implicates pasture feeding, allows feeding of only little supplementary hay and concentrate, and completely omits silage feeding. The farms were chosen within an area of almost 1,600 $\mathrm{km}^{2}$ of the Hyblean plateau of Ragusa province (Italy), the area being representative of the Sicilian grazing-based feeding systems and predominant pasture compositions. Fourteen Sicilian dairy farms were selected and allocated into 2 balanced groups on the basis of spontaneous (SPO) or cultivated (CULT) pasture type (PT). Sampling and data collection occurred 4 times at approximately 3 -wk intervals during the 2011 grazing season, on February 22 [test-day (TD)-1], March 15 (TD-2), April 6 (TD-3), and April 26 (TD-4). On each TD, bulk milk samples per farm (all of which milked twice a day) and feed samples, including pasture, hay, and concentrates, were collected. Milk samples were stored at $4^{\circ} \mathrm{C}$ protected from light until being analyzed the next day. Pasture botanical composition was estimated by trained personnel by identification of the 10 most abundant pasture plant families growing in the individual fields and estimation of their approximate proportions. A standardized questionnaire was submitted to farmers to report details about dairy herds and farm management such as number of animals, cow breed composition, diet composition, grazing hours, and milk production.

Pasture intake levels were estimated considering feed chemical analyses and milk yield and quality and feeding levels of hay and concentrates using CPM Dairy (version 3.0.8; Cornell University, Ithaca, NY; University of Pennsylvania, Kennett Square, PA; and William H. Miner Agricultural Research Institute, Chazy, NY). Details of feed and milk analyses are explained below. According to pasture intake (PI), spontaneous and cultivated PT farms were split into low pasture intake (LPI; $<29.5 \%$ of DM) and high pasture intake (HPI; $>29.5 \%$ of DM) groups. The LPI group included 4 CULT and 3 SPO farms, and the HPI group included 3 CULT and 4 SPO farms.

\section{Milk Analyses}

Bulk milk samples per farm were analyzed for fat contents by MilkoScan Minor (Foss, Padova, Italy). Extractions of both $\alpha$-tocopherol and $\beta$-carotene from milk samples were performed in darkness to avoid oxidation reactions, according to the Palozza and Krinsky (1992) procedure modified by Marino et al. (2010). Vitamin concentrations were determined by an HPLC method using an SB-C18 column $(5-\mu \mathrm{m}$ particle size, $4.6 \mathrm{~nm}$ i.d. $\times 250 \mathrm{~nm}$, Agilent Zorbax, Agilent Technologies, Santa Clara, CA). The HPLC system (Waters 2695; Waters, Milford, MA) was equipped with a multi-wavelength $(\lambda)$ fluorescence detector (Waters 2475 ) using an excitation wavelength of $297 \mathrm{~nm}$ and an emission wavelength of $340 \mathrm{~nm}$ for the detection of tocopherol isomers, equipped with a dual $\lambda$ absorbance detector (Waters 2487) using a wavelength of 450 $\mathrm{nm}$ for the detection of $\beta$-carotene. Identification and 
quantification of $\alpha$-tocopherol and all-trans- $\beta$-carotene was based on external standards obtained from Sigma (Sigma Chemical Co., St. Louis, MO).

\section{Forage and Feeds Analyses}

Bulk pasture samples were dried at $60^{\circ} \mathrm{C}$ to a constant weight. All feed samples were chemically analyzed to determine DM, NDF, and CP. Neutral detergent fiber was determined with a Fibertec (Foss, Hillerød, Denmark) fiber analyzer using reagents and method described by Van Soest et al. (1991). The CP content was determined with the Kjeldahl method (ISO, 2009).

\section{Statistical Analysis}

The data set was processed using JMP statistical software (version 8.0.1, SAS Institute Inc., Cary, NC) with PT group, PI group, sampling period $(\mathbf{S P})$, and the interactions $\mathrm{PT} \times \mathrm{PI}, \mathrm{PT} \times \mathrm{SP}$, and $\mathrm{PI} \times \mathrm{SP}$ as fixed effects, and farm as random effect. Differences in milk fat-soluble vitamin and fat contents, breed composition, diet composition including vitamin E supplement with concentrate, grazing time, pasture botanical and chemical composition, and milk yield were considered significant at $P<0.05$. All data are presented as least squares means and SEM.

\section{RESULTS AND DISCUSSION}

\section{Animals, Feeding Management, and Pasture Composition}

Numbers of farms and animals, cow breeds, dietary composition, grazing time, and pasture composition of the 4 groups are shown in Table 1 . Herds of both CULT and SPO management systems were mainly made up of Italian Friesian, Italian Brown, and, to a lesser extent, Italian Red Pied and crossbred dairy cows. Breed composition of farms within PT and PI groups was highly variable and not significantly different between the groups as a consequence.

Milk production of cows grazing CULT and SPO pasture was, on average, 26.4 and $21.7 \mathrm{~kg} / \mathrm{d}$, respectively. Milk production of cows fed LPI and HPI was, on average, 23.6 and $24.5 \mathrm{~kg} / \mathrm{d}$, respectively. However, these differences in milk yield of all 4 groups were not statistically significant. As a consequence, breed composition and milk production levels may not have confounded, to a great extent, the effects of feeding management on milk vitamin levels.

The cow dietary composition within the PT and PI groups consisted of pasture, commercial concentrate mix, and hay. We observed a trend for higher grazing time of the SPO compared with the CULT cows and, as a consequence, intake levels were different. The pasture intake level of SPO $(36.7 \%$ DM) was higher than CULT (29.4\% DM). However, pasture intake levels differed more in PI compared with PT groups. Pasture intake levels of the HPI and LPI groups were $43.5 \%$ and $22.6 \%$ DM, respectively. Within the HPI group, the average intake was higher on SPO farms than on CULT farms (49.7 vs. $37.2 \% \mathrm{DM}$, respectively). The difference in average intake between SPO and CULT farms (23.7 vs. $21.5 \%$ DM, respectively) allocated to the LPI group was not significant.

Concentrate and hay proportions fed were not different within the PT group, but did differ within the PI group. However, even though LPI cows were fed higher proportions of concentrate and hay compared with HPI cows, supplemental synthetic $\alpha$-tocopherol was similar. In contrast, compared with the SPO cows, CULT cows had similar levels of concentrates and hay but were fed higher levels of supplemental synthetic $\alpha$-tocopherol with the concentrates (44.6 vs. $28.1 \mathrm{mg} / \mathrm{kg}$ ). However, differences due to supplemental synthetic $\alpha$-tocopherol may be negligible because several authors report that synthetic $\alpha$-tocopherol is not transferred efficiently to milk (Slots et al., 2007; Vagni et al., 2011). We did not expect to observe an increase in milk $\alpha$-tocopherol due to synthetic $\alpha$-tocopherol feeding.

Pasture botanical composition was different in both pasture types. More than 13 plant families were identified in SPO pastures compared with 8 families in CULT pastures. The CULT pasture was mainly composed of the Poaceae family (82.8\%), including Avena hirsuta, Lolium perenne, Hordeum leporinum, and Triticum spp., and to a lesser extent by the Fabaceae family (11.5\%), including Medicago spp., Trifolium spp., and Vicia spp. Some spontaneous plant species belonging to Asteraceae, Cruciferae, Euphorbiaceae, Malvaceae, Polygonaceae and Umbelliferae were observed in the CULT pasture but only in small quantities (5.8\%). The SPO pasture was also dominated by the Poaceae $(29.2 \%)$ and Fabaceae $(30.9 \%)$ families. However, unlike the CULT pasture, SPO pasture also contained Boraginaceae (1.7\%), Geraniaceae (1.2\%), Oxalidaceae $(1.2 \%)$, Ranunculaceae $(0.4 \%)$, and Liliaceae $(0.2 \%)$ as well as higher percentages of Asteraceae (18\%), Cruciferae (5.5\%), Euphorbiaceae (4.0\%), Malvaceae (3.1\%), Umbelliferae $(2.3 \%)$, and Polygonaceae (1.7\%).

\section{Effect of Pasture Type on Milk Fat-Soluble Vitamins}

Table 1 shows the levels of $\alpha$-tocopherol and $\beta$-carotene in milk and milk fat. In the present study, the levels of $\alpha$-tocopherol ranged from 0.3 to $1.0 \mathrm{mg} / \mathrm{L}$ in milk and from 10.0 to $27.2 \mathrm{mg} / \mathrm{kg}$ in milk fat, respec- 
Table 1. Description of experimental conditions, milk production and quality in relationship to pasture type (PT) and pasture intake (PI) ${ }^{1}$

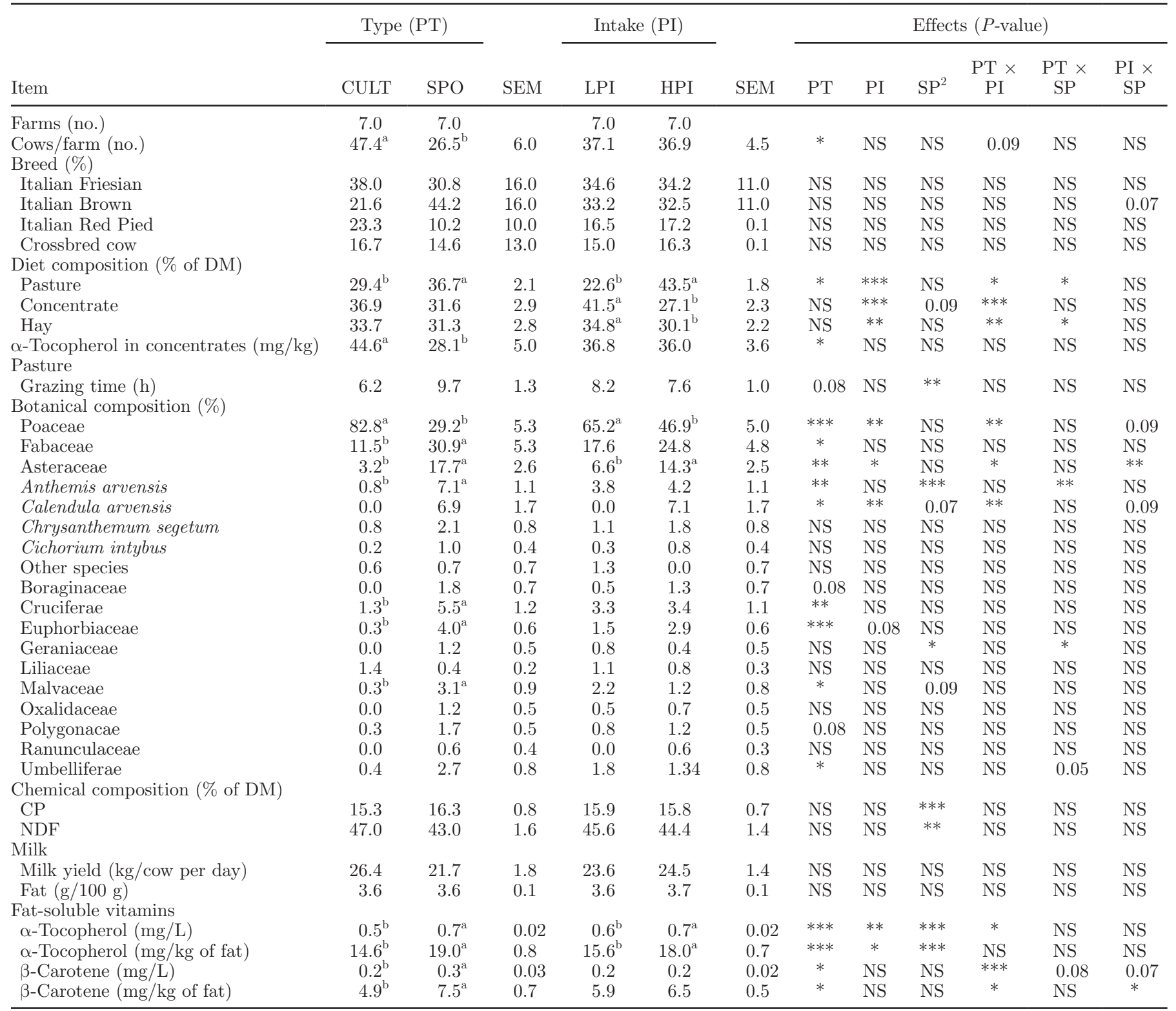

${ }_{\mathrm{a}, \mathrm{b}}$ Least squares means within a row with different superscripts differ $(P<0.05)$.

${ }^{1}$ CULT $=$ cultivated pasture; $\mathrm{SPO}=$ spontaneous pasture; LPI $=$ low pasture intake, $<29.5 \% \mathrm{DM} ; \mathrm{HPI}=$ high pasture intake, $>29.5 \%$ DM.

${ }^{2} \mathrm{SP}=$ sampling period.

${ }^{*} P<0.05 ;{ }^{* *} P<0.01 ;{ }^{* * *} P<0.001$.

tively. The levels of all-trans- $\beta$-carotene ranged from 0.05 to $0.5 \mathrm{mg} / \mathrm{L}$ in milk and from 1.6 to $12.1 \mathrm{mg} / \mathrm{kg}$ in milk fat, respectively. Similar levels of $\alpha$-tocopherol and $\beta$-carotene in pasture milk were reported by Marino et al. (2012). We observed no pasture type or intake effects on milk yield or milk fat. Observed differences in milk vitamin contents were therefore driven exclusively by the tested variables.

The $\beta$-carotene levels of milk and milk fat were 33.3 and $34.6 \%$, respectively, and were higher in SPO com- pared with the CULT group. The $\alpha$-tocopherol levels in milk and milk fat were 28.6 and $23.1 \%$, respectively, again higher in SPO compared with the CULT group. As reported before, the CULT cows had a higher supplementation of synthetic $\alpha$-tocopherol compared with the SPO cows and, considering this difference, the effects of pasture type on milk and milk fat $\alpha$-tocopherol may be greater than the effects observed in this study. On the other hand, Slots et al. (2007) and Vagni et al. (2011) reported that synthetic $\alpha$-tocopherol stereoisomers in 
the diet are transferred with low efficiency to milk compared with natural $\alpha$-tocopherol stereoisomers.

As discussed before, the difference in pasture intake levels between SPO and CULT groups may, in part, explain the $\alpha$-tocopherol variations in milk. Pasture intake increased $24.8 \%$ in the SPO group compared with the CULT group and $\alpha$-tocopherol increased $28.6 \%$ in the respective milk samples. On the other hand, the pasture intake difference between the LPI and HPI groups was much higher, but milk $\alpha$-tocopherol responses were more moderate. The HPI group had a 92.5\% higher pasture intake compared with the LPI group, but milk $\alpha$-tocopherol was only $14.3 \%$ higher. Thus, the differences in milk $\alpha$-tocopherol content were a consequence of both PI and PT. Differences in botanical composition of both pasture types may explain the PT effect. The SPO pastures had a more heterogeneous composition compared with the CULT pastures. Martin et al. (2004) reported higher levels of fat-soluble vitamins and higher PUFA levels in milk from native pasture compared with concentrate, with ryegrass hay and with diets rich in native grass and hay. Havemose et al. (2006) reported that increasing proportions of PUFA in feed increased the transfer of $\alpha$-tocopherol from feed to milk. Several authors indicate that a higher botanical diversity of fresh pasture is associated with higher concentrations of PUFA in dairy products (Collomb et al., 2002). Tornambé et al. (2007) reported higher PUFA levels in milk of animals grazing pasture with higher botanical diversity compared with monocultures. In general, it seems that responses in milk fat-soluble vitamin levels to feeding regimen are positively related to the responses in milk PUFA levels, although this is controversial. For example, Al Mabruk et al. (2004) found that red clover and lucerne compared with grass-based diets decreased milk oxidative stability during storage, indicating lower antioxidant levels, even though legume-rich diets were better sources of fat-soluble vitamins compared with grasses. An explanation for this discrepant finding could be a higher content of easily oxidizable PUFA in milk from legume-rich diets, as reported by Havemose et al. (2006). Moorby et al. (2009) found that red clover affected milk oxidative stability only slightly compared with grass-based diets.

The proportions of Asteraceae plant biomass distributed in the 4 groups followed a similar trend as milk $\alpha$-tocopherol and $\beta$-carotene levels in milk and milk fat (Figures 1, 2A and 2B). In all 4 groups of the present study, the main plant families had different distributions, as shown in Figure 3. The HPI relative to LPI SPO fields had a higher percentage of Asteraceae plant biomass (26.0 vs. $9.4 \%$, respectively), but HPI and LPI fields of the CULT farms did not differ (2.5 vs. $3.8 \%$ ). Furthermore, we observed no differences in Asteraceae plant biomass between CULT and SPO fields allocated to the LPI group or between CULT HPI and SPO LPI fields. In addition, in the SPO group, HPI relative to LPI fields had a lower percentage of Poaceae (10.9 vs. $47.5 \%$, respectively), but the botanical composition between HPI and LPI pastures in the CULT group did not differ. In general, the CULT group contained a higher Poaceae plant biomass compared with the SPO group (82.8 vs. $29.2 \%$, respectively). Poaceae plants contain higher levels of fiber and may limit pasture intake compared with Asteraceae plants (Licitra et al., 1997). Moreover, Asteraceae plants present in HPI farms of the SPO group consisted mainly of Calendula arvensis (14\%). Licitra et al. (1997) reported Calendula arvensis to be the most abundant species present in Hyblean native pasture. It contains high levels of $\beta$-carotene besides flavonoids and essential oils (Muley et al., 2009; Butnariu and Coradini, 2012), and this particular Asteraceae species may have increased vitamin levels in milk and milk fat.

\section{Pasture Intake Effect on Milk Fat-Soluble Vitamins}

In the present study, $\alpha$-tocopherol in milk fat was the only tested vitamin affected by PI independently of PT (Table 1). High pasture intake slightly increased Q-tocopherol content by 14.8 and $13.7 \%$ in milk and milk fat, respectively, compared with LPI (Table 1). These results were consistent with those reported by Weiss and Wyatt (2003) and Marino et al. (2012). In contrast to $\alpha$-tocopherol in milk fat, $\alpha$-tocopherol in milk and $\beta$-carotene in milk and milk fat were affected by pasture intake only in the SPO group, not in the CULT group (Table 1). When SPO was fed at HPI

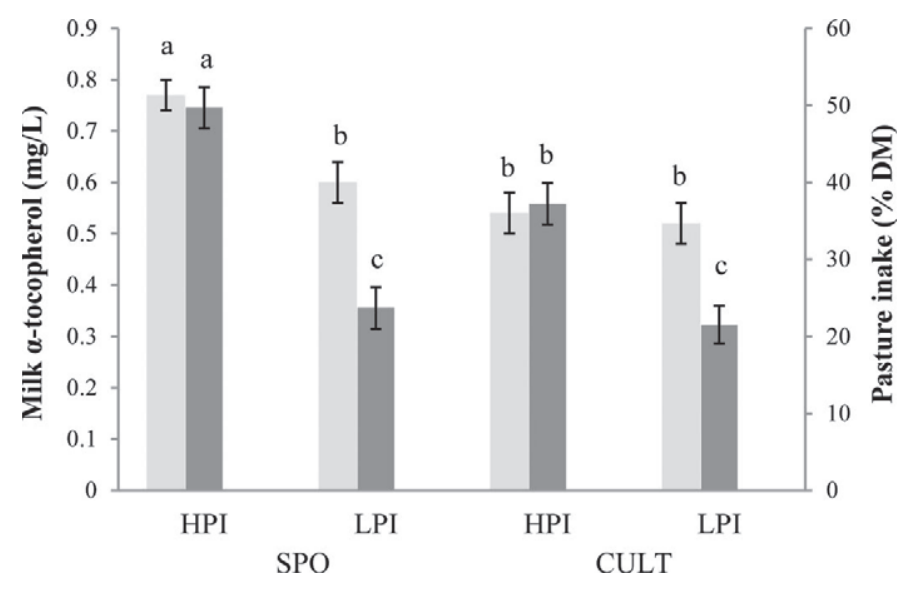

Figure 1. Milk $\alpha$-tocopherol content (light gray bars) from spontaneous (SPO) and cultivated (CULT) dairy farms with high and low pasture intake (dark gray bars). HPI $=$ high pasture intake, $>29.5 \%$ DM; LPI = low pasture intake, $<29.5 \%$ DM. ${ }^{\mathrm{a}-\mathrm{c}}$ Bars with different letters differ $(P<0.05)$. 


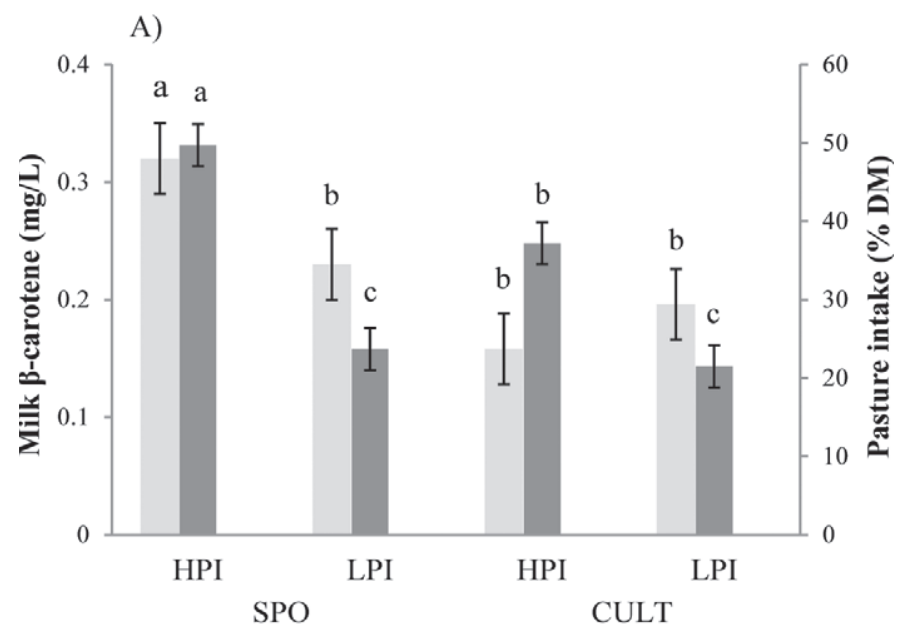

B)

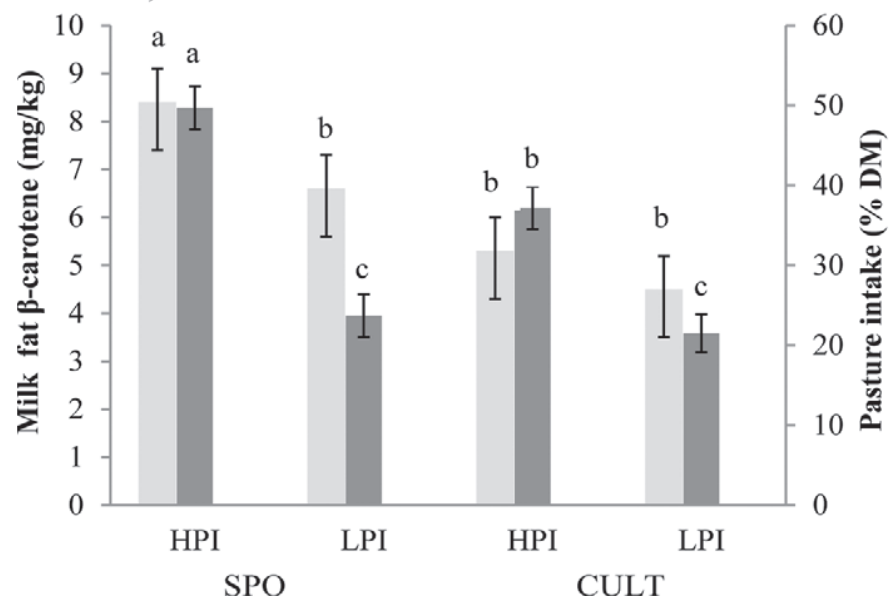

Figure 2. Content of $\beta$-carotene (light gray bars) in (A) milk and (B) milk fat from spontaneous (SPO) and cultivated (CULT) dairy farms with high and low pasture intake (dark gray bars). HPI = high pasture intake, $>29.5 \% \mathrm{DM}$; LPI $=$ low pasture intake, $<29.5 \% \mathrm{DM}$. ${ }^{\mathrm{a}-\mathrm{c}}$ Bars with different letters differ $(P<0.05)$.

(49.7\% DM) compared with SPO at LPI $(23.7 \%$ DM; Figure $2 \mathrm{~B}$ ), increasing the pasture intake by $110 \%$, the $\alpha$-tocopherol and $\beta$-carotene contents increased in milk by 22.8 and $27.8 \%$, respectively (Figures 1 and $2 \mathrm{~A}$ ), and the $\beta$-carotene content in milk fat by $21.5 \%$. On the other hand, when CULT pasture was fed, we observed no difference in any milk or milk fat vitamin content between HPI (37.2\% DM) and LPI (21.5\% DM) even though pasture intake differed by $73 \%$ DM. Comparing the CULT HPI group and the SPO LPI, milk and milk fat vitamin levels still did not differ, even though pasture intake differed by $57 \%$ DM. The lack of response in CULT at different intake levels and in CULT at HPI relative to SPO at LPI could be attributed to a PI difference that was not sufficiently high, to the pasture type and botanical composition, or both. Therefore,

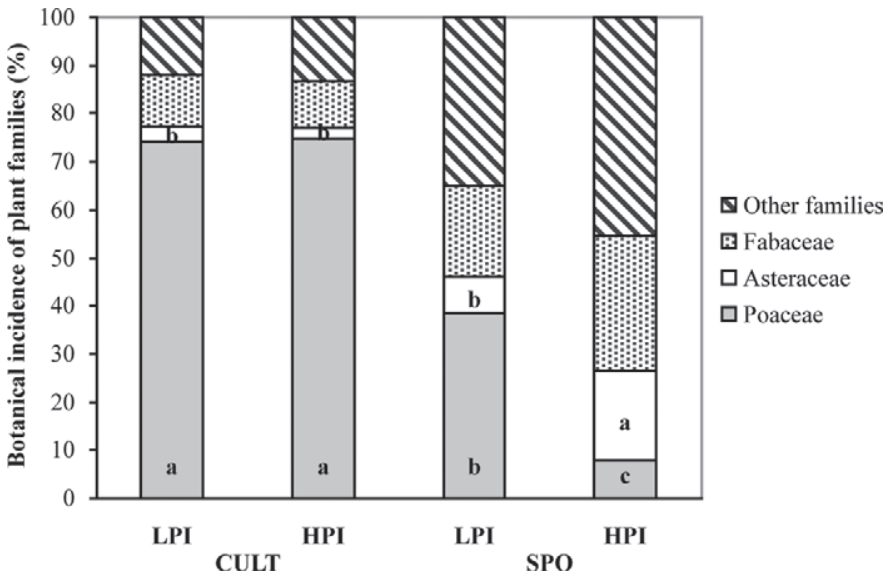

Figure 3. Incidence of main plant families in cultivated (CULT) and spontaneous (SPO) pastures of farms with high and low pasture intake situations. HPI $=$ high pasture intake, $>29.5 \% \mathrm{DM}$; LPI $=$ low pasture intake, $<29.5 \% \mathrm{DM}$. The areas inside bar represent the average incidences of single plant families within group. ${ }^{\mathrm{a}-\mathrm{c}}$ Areas with different letters differ $(P<0.05)$.

milk vitamin levels depended on both pasture intake and pasture type. A minimum PI level dependent on pasture botanical composition and PT may be necessary to influence levels of milk fat-soluble vitamins.

In the present study, SPO milk fat from HPI farms had levels of $\beta$-carotene similar to those reported by Slots et al. (2009) and Marino et al. (2012), even though pasture intakes were higher in the latter studies. Pasture intake in the HPI farms of the SPO group was $50 \%$ DM, whereas those reported by Slots et al. (2009) and Marino et al. (2012) were 94 and $69 \%$ DM, respectively. Calderón et al. (2007) listed several mechanisms that could limit the secretion of $\beta$-carotene into milk, especially in high carotenoid diets, indicating that there could be a limit to carotene uptake.

In the LPI group, we observed no difference in milk $\alpha$-tocopherol and $\beta$-carotene contents in milk and milk fat between SPO and CULT. These results were consistent with those of Slots et al. (2009) and Adler et al. (2010). Adler et al. (2010) did not find a significant effect of pasture botanical composition on milk fat-soluble vitamin content at pasture intake levels of only $15 \%$ DM. Slots et al. (2009) did not observe variation of milk $\beta$-carotene content between conventional and organic milk production systems at pasture intake levels of 4 and $16 \% \mathrm{DM}$, respectively. $\beta$-Carotene is a precursor of vitamin A, and Lucas et al. (2006) showed that $\beta$-carotene 15,15'-dioxygenase activity (which transforms $\beta$-carotene into vitamin $\mathrm{A}$ ) is higher in diets poor in $\beta$-carotene. This could explain the apparently low influence of pasture botanical composition at low pasture intake levels on milk vitamin contents in the present study. 
Table 2. Description of experimental conditions and milk production and quality in relationship to test day (TD)

\begin{tabular}{|c|c|c|c|c|c|}
\hline \multirow[b]{2}{*}{ Item } & \multicolumn{4}{|c|}{ Sampling period ${ }^{1}$} & \multirow[b]{2}{*}{ SEM } \\
\hline & TD-1 & TD-2 & TD-3 & TD-4 & \\
\hline Farms (no.) & 14.0 & 14.0 & 14.0 & 14.0 & \\
\hline Cows/farm (no.) & 36.4 & 37.4 & 37.8 & 36.3 & 4.4 \\
\hline \multicolumn{6}{|l|}{ Breed $(\%)$} \\
\hline Italian Friesian & 33.0 & 33.2 & 34.9 & 36.5 & 11.0 \\
\hline Italian Brown & 32.5 & 32.5 & 32.8 & 33.8 & 11.5 \\
\hline Italian Red Pied & 17.5 & 17.9 & 16.5 & 15.6 & 0.1 \\
\hline Crossbred cow & 16.7 & 16.4 & 15.6 & 13.9 & 0.1 \\
\hline \multicolumn{6}{|l|}{ Diet composition ( $\%$ of DM) } \\
\hline Pasture & 33.4 & 31.0 & 33.7 & 34.1 & 1.4 \\
\hline Concentrate & 35.3 & 36.3 & 33.4 & 33.1 & 2.3 \\
\hline Hay & 31.4 & 32.8 & 33.0 & 32.7 & 2.1 \\
\hline$\alpha$-Tocopherol in concentrates $(\mathrm{mg} / \mathrm{kg})$ & 36.4 & 35.7 & 36.6 & 36.6 & 3.5 \\
\hline \multicolumn{6}{|l|}{ Pasture } \\
\hline Grazing time $(\mathrm{h})$ & $7.4^{\mathrm{b}}$ & $7.3^{\mathrm{b}}$ & $7.4^{\mathrm{b}}$ & $9.6^{\mathrm{a}}$ & 1.0 \\
\hline \multicolumn{6}{|l|}{ Botanical composition (\%) } \\
\hline Poaceae & 62.8 & 52.5 & 54.0 & 54.7 & 5.3 \\
\hline Fabaceae & 17.6 & 25.6 & 22.5 & 19.1 & 4.5 \\
\hline Asteraceae & 11.4 & 8.9 & 6.8 & 14.6 & 3.0 \\
\hline Anthemis arvensis & $1.3^{\mathrm{b}}$ & $0.7^{\mathrm{b}}$ & $4.1^{\mathrm{b}}$ & $9.8^{\mathrm{a}}$ & 1.5 \\
\hline Calendula arvensis & 8.8 & 3.0 & 0.8 & 1.2 & 2.3 \\
\hline Chrysanthemum segetum & 0.6 & 2.1 & 1.4 & 1.7 & 0.9 \\
\hline Cichorium intybus & 0.6 & 0.5 & 0.3 & 0.8 & 0.5 \\
\hline Other species & 0.0 & 1.3 & 0.4 & 1.0 & 1.0 \\
\hline Boraginaceae & 1.1 & 3.3 & 0.7 & 2.9 & 1.0 \\
\hline Cruciferae & 1.9 & 2.8 & 5.2 & 3.6 & 1.6 \\
\hline Euphorbiaceae & 2.2 & 1.6 & 2.8 & 2.1 & 0.7 \\
\hline Geraniaceae & 0.0 & $1.8^{\mathrm{a}}$ & $0.4^{\mathrm{b}}$ & $0.02^{\mathrm{b}}$ & 0.5 \\
\hline Liliaceae & 0.4 & 0.0 & 0.0 & 0.0 & 0.2 \\
\hline Malvaceae & 0.7 & 3.5 & 1.7 & 0.9 & 0.9 \\
\hline Oxalidaceae & 1.4 & 0.4 & 0.7 & 0.0 & 0.7 \\
\hline Polygonacae & 0.0 & 1.5 & 1.9 & 0.8 & 0.7 \\
\hline Ranunculaceae & 1.2 & 0.0 & 0.0 & 0.0 & 0.5 \\
\hline Umbelliferae & 0.0 & 1.2 & 3.6 & 1.4 & 1.1 \\
\hline \multicolumn{6}{|l|}{ Chemical composition ( $\%$ of DM) } \\
\hline $\mathrm{CP}$ & $17.7^{\mathrm{a}}$ & $17.3^{\mathrm{a}}$ & $15.6^{\mathrm{b}}$ & $12.8^{\mathrm{c}}$ & 0.7 \\
\hline NDF & $42.6^{\mathrm{b}}$ & $44.8^{\mathrm{b}}$ & $44.1^{\mathrm{b}}$ & $48.6^{\mathrm{a}}$ & 1.4 \\
\hline \multicolumn{6}{|l|}{ Milk } \\
\hline Milk yield (kg/cow per day) & 23.7 & 24.0 & 24.3 & 24.2 & 1.4 \\
\hline Fat $(\mathrm{g} / 100 \mathrm{~g})$ & 3.6 & 3.7 & 3.6 & 3.6 & 0.1 \\
\hline \multicolumn{6}{|l|}{ Fat-soluble vitamins } \\
\hline$\alpha$-Tocopherol (mg/L) & $0.7^{\mathrm{a}}$ & $0.6^{\mathrm{a}}$ & $0.5^{\mathrm{b}}$ & $0.6^{\mathrm{a}}$ & 0.0 \\
\hline$\alpha$-Tocopherol (mg/kg of fat) & $18.6^{\mathrm{a}}$ & $17.5^{\mathrm{a}}$ & $13.6^{\mathrm{b}}$ & $17.5^{\mathrm{a}}$ & 0.8 \\
\hline$\beta$-Carotene $(\mathrm{mg} / \mathrm{L})$ & 0.2 & 0.2 & 0.2 & 0.2 & 0.0 \\
\hline$\beta$-Carotene (mg/kg of fat) & 6.3 & 6.5 & 5.9 & 6.1 & 0.5 \\
\hline
\end{tabular}

${ }^{\mathrm{a}-\mathrm{c}}$ Least squares means within a row with different superscripts differ $(P<0.05)$.

${ }^{1}$ TD-1 = February 22, 2011; TD-2 = March 15, 2011; TD-3 = April 6, 2011; TD-4 = April $26,2011$.

\section{Period Effect on Milk Fat-Soluble Vitamins}

Period influenced milk and milk fat $\alpha$-tocopherol levels (Table 2). We observed a significant decrease in milk and milk fat $\alpha$-tocopherol $(24.5$ and $23.7 \%$, respectively) at TD-3 compared with TD-1, TD-2, and TD-4, which could be related to variations in pasture botanical composition in combination with changes in the biological plant maturity stages during the experimental period (Table 2). However, other factors such as animal health status and average cow physiological stage may have influenced milk $\alpha$-tocopherol levels but these were not measured and taken into consideration in the present study.

The PI effect on milk fat $\beta$-carotene was linked to period. Figure 4 shows that milk fat $\beta$-carotene content was significantly $(20.3 \%)$ higher only at TD-1 in the HPI group compared with the LPI group. This result may be again explained by the variations in botanical composition. In particular, we found a difference in Asteraceae plant proportion between HPI and LPI fields (23.4 vs. $0 \%$, respectively; Figure 5 ) only on TD-1. As 
550

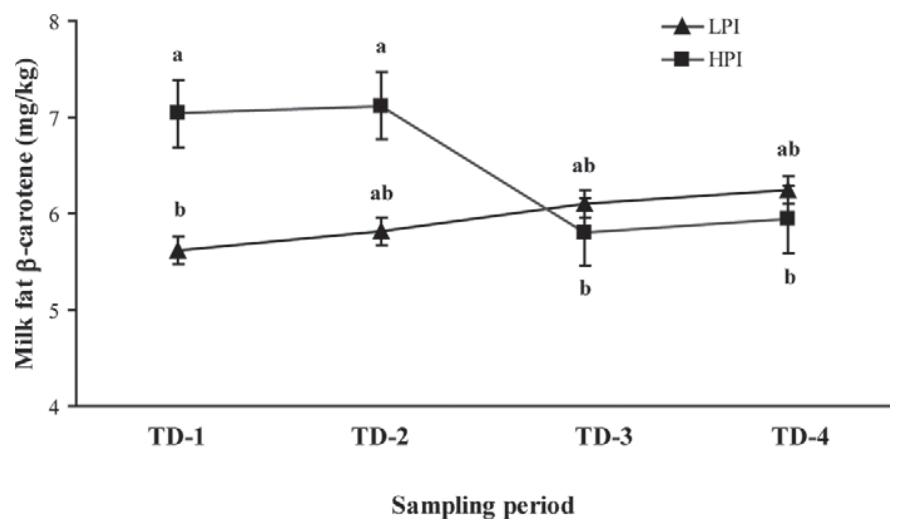

Figure 4. Content of milk fat $\beta$-carotene from farms with high (HPI) and low pasture intake (LPI) situations throughout the experimental period. $\mathrm{HPI}=$ high pasture intake, $>29.5 \% \mathrm{DM}$; LPI $=$ low pasture intake, $<29.5 \%$ DM. Test-day (TD)-1 = February 22, 2011; TD-2 = March 15, 2001; TD-3 = April 6, 2011; TD-4 = April 26, 2011. Results are least squares means of 14 measurements per test day ${ }^{\mathrm{a}, \mathrm{b}}$ Significant differences are shown with different letters $(P<0.05)$.

explained above, the Asteraceae family could influence the $\beta$-carotene content in milk but high levels of intake may be necessary to achieve such a change.

In addition, we observed differences in milk fat $\beta$-carotene content between TD, but only within the HPI group. This latter result cannot be explained by differences in Asteraceae proportions between TD. At TD-3 and TD-4 in the HPI group, milk fat $\beta$-carotene content (5.8 and $5.9 \mathrm{mg} / \mathrm{kg}$ of fat, respectively) decreased compared with the first 2 TD (7.0 and 7.1 $\mathrm{mg} / \mathrm{kg}$ fat, respectively; Figure 4), but the Asteraceae

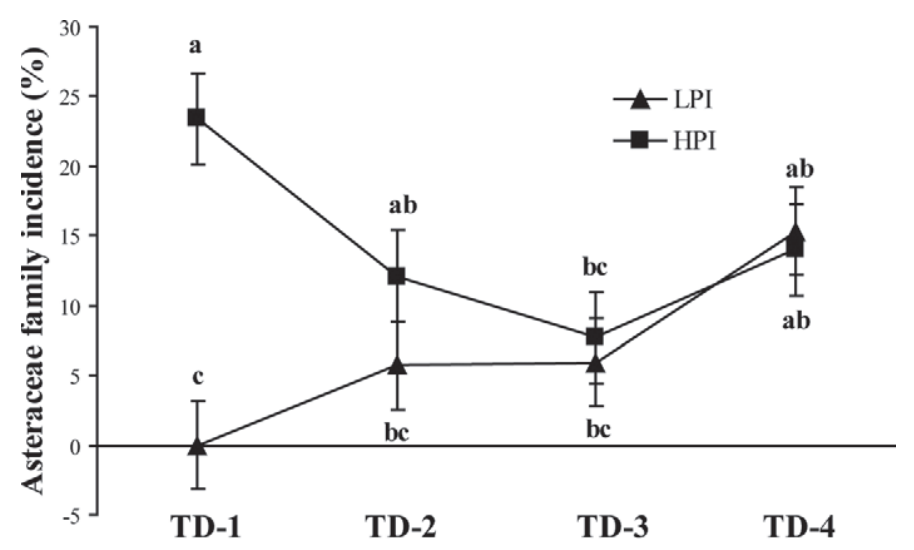

Sampling period

Figure 5. Asteraceae family incidence in farms with high (HPI) and low pasture intake (LPI) situations throughout the experimental period. HPI $=$ high pasture intake, $>29.5 \%$ DM; LPI $=$ low pasture intake, $<29.5 \%$ DM. Test-day (TD)-1 = February 22, 2011; TD-2 = March 15, 2001; TD-3 = April 6, 2011; TD-4 = April 26, 2011. Results are least squares means of 14 measurements per test day. ${ }^{\mathrm{a}-\mathrm{c}}$ Significant differences are shown with different letters $(P<0.05)$. proportions in HPI fields were lower on TD-3 (but not TD-4) compared with TD-1 (Figure 5). The advancement in pasture maturity stage could explain the milk fat $\beta$-carotene contents in the HPI group. At TD-3 and TD-4, pasture CP content decreased compared with that on TD-1 and TD-2, and NDF content increased on TD-4 compared with the other TD (Table 2). This is in accordance with Calderón et al. (2006), who suggested that $\beta$-carotene content in milk may be related to evolution in forage maturity stage and to the respective decrease in digestibility.

\section{CONCLUSIONS}

Milk and milk fat from SPO compared with CULT pastures contained higher amounts of $\alpha$-tocopherol and $\beta$-carotene. These results may be explained by the different botanical composition and plant maturity stage in combination with pasture intake. Spontaneous pastures fields contained less Poaceae and more Fabaceae, Asteraceae, Cruciferae, Euphorbiaceae, and Malvaceae plant biomass than did CULT pastures. The occurrence of the Asteraceae plant family, especially, in pasture fields greatly affected milk vitamin levels. Vitamin levels of pasture types and individual plant species were not measured in the current study but this should be considered for future studies to establish a clear association between pasture composition and occurrence of individual species to milk vitamin contents. Only in the SPO but not in the CULT milk, HPI increased $\alpha$-tocopherol in milk and $\beta$-carotene in milk and milk fat, especially in February and March probably in relation to plant biological stage. High compared with low pasture intake increased $\alpha$-tocopherol in milk fat. However, in the present study pasture type and intake effects were in part confounded and future studies under controlled conditions are needed to evaluate and distinguish both effects. In general, feeding high levels of spontaneous pastures of dairy cows may be a good strategy to produce dairy products with a high content of antioxidants.

\section{ACKNOWLEDGMENTS}

This research was funded by the "Assessorato Agricolture e Foreste" of the Sicilian Region (Palermo, Italy).

\section{REFERENCES}

Adler, S., A. V. Dahl, A. H. Vae, E. Thuen, T. Garmo, S. Krogh-Jensen, J. Hansen-Møller, and H. Steinshamn. 2010. Effect of pasture botanical composition on milk composition in organic production. Grassl. Sci. Eur. 15:425-427.

Agabriel, C., A. Cornu, C. Journal, C. Sibra, P. Grolier, and B. Martin. 2007. Tanker milk variability according to farm feeding prac- 
tices: Vitamins A and E, carotenoids, color, and terpenoids. J. Dairy Sci. 90:4884-4896.

Al-Mabruk, R. M., N. F. G. Beck, and R. J. Dewhurst. 2004. Effects of silage species and supplemental vitamin $\mathrm{E}$ on the oxidative stability in milk. J. Dairy Sci. 87:406-412.

Ballet, N., J. C. Robert, and P. E. V. Williams. 2000. Vitamins in forages. Pages 399-431 in Forage Evaluation in Ruminant Nutrition. D. I. Givens, E. Owen, R. F. E. Axford, and H. M. Omed, ed. CAB International, Wallingford, UK.

Bhat, Z. F., and H. Bhat. 2011. Milk and dairy products as functional foods: A review. Int. J. Dairy Sci. 6:1-12.

Butnariu, M., and C. Z. Coradini. 2012. Evaluation of biologically active compounds from Calendula officinalis flowers using spectrophotometry. Chem. Cent. J. 6:35.

Calderón, F., B. Chauveau-Duriot, B. Martin, B. Graulet, M. Doreau, and P. Noziere. 2007. Variations in carotenoids, vitamins A and $\mathrm{E}$, and color in cow's plasma and milk during late pregnancy and the first three months of lactation. J. Dairy Sci. 90:2335-2346.

Calderón, F., G. Tornambé, B. Martin, P. Pradel, B. Chauveau-Duriot, and P. Nozière. 2006. Effects of mountain grassland maturity stage and grazing management on carotenoids in sward and cow's milk. Anim. Res. 55:533-544.

Collomb, M., U. Bútikofer, R. Sieber, B. Jeangros, and J. O. Bosset. 2002. Correlation between fatty acids in cows' milk fat produced in the Lowlands, Mountains and Highlands of Switzerland and botanical composition of the fodder. Int. Dairy J. 12:661-666.

Ellis, K. A., A. Monteiro, G. T. Innocent, D. Grove-White, P. Cripps, W. G. Mclean, C. V. Howard, and M. Mihmz. 2007. Investigation of the vitamins $\mathrm{A}$ and $\mathrm{E}$ and $\beta$-carotene content in milk from UK organic and conventional dairy farms. J. Dairy Res. 74:484-491.

Havemose, M. S., M. R. Weisbjerg, W. L. Bredie, H. D. Poulsen, and J. H. Nielsen. 2006. Oxidative stability of milk influenced by fatty acids, antioxidants, and copper derived from feed. J. Dairy Sci. 89:1970-1980.

ISO (International Organization for Standardization). 2009. EN ISO 5983-2:2009: Animal feeding stuffs - Determination of nitrogen content and calculation of crude protein content. ISO, Geneva, Switzerland.

Licitra, G., S. Carpino, I. Schadt, M. Avondo, and S. Barresi. 1997. Forage quality of native pastures in a Mediterranean area. Anim. Feed Sci. Technol. 69:315-328.

Lindmark-Månsson, H., and B. Åkesson. 2000. Antioxidative factors in milk. Br. J. Nutr. 84:S103-S110.

Lucas, A., C. Agabriel, B. Martin, A. Ferlay, I. Verdier-Metz, J. B. Coulon, and E. Rock. 2006. Relationships between the conditions of cow's milk production and the contents of components of nutritional interest in raw milk farmhouse cheese. Lait 86:177-202.

Marino, V. M., S. La Terra, G. Licitra, and S. Carpino. 2010. Effetto del trattamento termico sulle sostanze nutraceutiche del latte. Sci. Tecn. Latt. Cas. 61:19-27.

Marino, V. M., I. Schadt, S. La Terra, M. Manenti, M. Caccamo, G. Licitra, and S. Carpino. 2012. Influence of season and pasture feeding on the content of $\alpha$-tocopherol and $\beta$-carotene in milk from Holstein, Brown Swiss and Modicana cows in Sicily. J. Dairy Sci. Technol. 92:501-513.

Martin, B., V. Fedele, A. Ferlay, P. Grolier, E. Rock, D. Gruffat, and Y. Chilliard. 2004. Effects of grass-based diets on the content of micronutrients and fatty acids in bovine and caprine dairy products. Grassl. Sci. Eur. 9:876-886.

Moorby, J. M., M. R. F. Lee, D. R. Davies, E. J. Kim, G. R. Nute, N. M. Ellis, and N. D. Scollan. 2009. Assessment of dietary ratios of red clover and grass silages on milk production and milk quality in dairy cows. J. Dairy Sci. 92:1148-1160.

Muley, B. P., S. S. Khadabadi, and N. B. Banarase. 2009. Phytochemical constituents and pharmacological activities of $C$. officinalis Linn (Asteraceae): A review. Trop. J. Pharm. Res. 8:455-465.

Nozière, P., B. Graulet, A. Lucas, B. Martin, P. Grolier, and M Doreau. 2006. Carotenoids for ruminants: From forages to dairy products. Anim. Feed Sci. Technol. 131:418-450.

Palozza, P., and N. I. Krinsky. 1992. $\beta$-Carotene and tocopherol are synergistic antioxidants . Arch. Biochem. Biophys. 297:184-187.

Slots, T., G. Butler, C. Leifert, T. Kristensen, L. H. Skibsted, and J. H. Nielsen. 2009. Potentials to differentiate milk composition by different feeding strategies. J. Dairy Sci. 92:2057-2066.

Slots, T., L. H. Skibsted, and J. H. Nielsen. 2007. The difference in transfer of all-rac- $\alpha$-tocopherol stereo-isomers to milk from cows and the effect on its oxidative stability. Int. Dairy J. 17:737-745.

Tornambé, G., A. Ferlay, A. Farruggia, Y. Chilliard, P. Loiseau, J. P. Garel, and B. Martin. 2007. Effet de la diversite floristique des paturages de montagne sur le profil en acides gras et les caracteristiques sensorielles des laits. Ren. Rec. Rumin. 14:333-336.

Vagni, S., F. Saccone, L. Pinotti, and A. Baldi. 2011. Vitamin E bioavailability: Past and present insights. Food Nutr Sci. 2:10881096.

Van Soest, P. J., J. B. Robertson, and B. A. Lewis. 1991. Methods for dietary fiber, neutral detergent fiber and nonstarch polysaccharides in relation to animal nutrition. J. Dairy Sci. 74:3583-3597.

Weiss, W. P., and D. J. Wyatt. 2003. Effect of dietary fat and vitamin E on alpha-tocopherol in milk from dairy cows. J. Dairy Sci. $86: 3582-3591$. 